\title{
CDISC SDTM Tumor Identification Test Name Terminology
}

National Cancer Institute

\section{Source}

National Cancer Institute. CDISC SDTM Tumor Identification Test Name Terminology. NCI Thesaurus. Code C96783.

Terminology associated with the tumor identification test name codelist of the Clinical Data Interchange Standards Consortium (CDISC) Study Data Tabulation Model (SDT M). 